Article

\title{
Optimisation of Radium Removal from Saline Produced Waters during Oil and Gas Extraction
}

\author{
Joel Garner ${ }^{1}$ and David Read ${ }^{2,3, *}$ \\ 1 Aurora Health Physics, Harwell Oxford, Didcot OX11 0SG, UK; joel.garner@aurorahp.co.uk \\ 2 Department of Chemistry, University of Surrey, Guildford GU2 7XH, UK \\ 3 National Physical Laboratory, Teddington TW11 0LW, UK \\ * Correspondence: d.read@surrey.ac.uk; Tel.: +44-1483-683451
}

Received: 3 February 2020; Accepted: 9 March 2020; Published: 19 March 2020

\begin{abstract}
Unconventional shale gas exploitation presents complex problems in terms of radioactive waste disposal. Large volumes of saline produced water resulting from hydraulic fracturing are typically enriched in radium isotopes, up to several hundred $\mathrm{Bq} / \mathrm{dm}^{3}$, orders of magnitude above national discharge limits. There is a need, therefore, to decontaminate the fluid prior to discharge, preferably by creating a less problematic radium-containing, solid waste form. Barite (barium sulphate) co-precipitation is a cost-effective method for achieving these objectives, provided the process can be controlled. In this work, radium recovery of $\sim 90 \%$ has been achieved for simulant produced waters containing $100 \mathrm{~Bq} / \mathrm{dm}^{3}$, using a single, optimised co-precipitation step. However, salinity has a significant effect on the efficiency of the process; higher salinity solutions requiring substantially more reagent to achieve the same recovery. If $>90 \%$ radium removal is sought, multiple co-precipitation steps provide a much faster alternative than post-precipitation recrystallization of the barite solid phase, albeit at higher cost. The resulting solid waste has a relatively high specific radium activity but a much smaller volume, which presents a less intractable disposal problem for site operators than large volumes of radium-contaminated fluid.
\end{abstract}

Keywords: shale gas; radioactive waste; radium; contaminated fluids

\section{Introduction}

In 1904, shortly after the discovery of radioactivity, thermal brines co-produced with oil and gas were found to be enriched in natural radioactive isotopes [1,2]. Over the last century, naturally occurring radioactive material (NORM) has been discovered at oil and gas production sites globally, presenting a significant radiological protection and waste disposal problem (e.g., [3-5]). The vast majority of production sites affected by NORM in Europe employ conventional extraction techniques and are located offshore, allowing permitted sea disposal of up to $90 \%$ of the radioactive waste generated [5]. In the United States, onshore production is often accompanied by re-injection of flow-back and produced waters, thereby reducing the volume of potentially contaminated water that needs to be treated on site (e.g., [4]). With one historical exception [6], this option is not available at onshore wells in the UK, owing to the greater population density and aquifer vulnerability [7]. The recent expansion of hydraulic fracturing or 'fracking' in the USA and attempts by other countries to emulate it, has the potential to generate very large volumes of highly saline, radium-containing produced water in addition to scaled pipework and other equipment. Moreover, the aggressive nature of the extraction method [8] tends to lead to higher activity concentrations of the principal isotopes; radium-226 $\left({ }^{226} \mathrm{Ra}\right)$ and radium-228 $\left({ }^{228} \mathrm{Ra}\right)$. Activity levels in produced water from the Marcellus Shale in the United States [4] and from preliminary testing of the UK's Bowland Shale [9] have been shown to exceed national exemption limits for aqueous discharge by a substantial margin $[10,11]$. This raises two main 
problems. First, as storage capacity at any given production site is limited, there is a need to treat it, either by re-injecting it or by removing radium from the fluid and transforming it into a lower volume, solid waste form that is more manageable. Second, the low discharge limits for ${ }^{226 / 228} \mathrm{Ra}$, particularly in the UK $\left(10 \mathrm{mBq} / \mathrm{dm}^{3}\right)$, present an analytical challenge; typically, several separation and concentration steps are required before analysis [12]. This, in turn, makes on-site compliance measurements of the residual fluid highly problematic.

Hydraulic fracturing involves pumping large quantities of fracking fluid down a borehole at high pressure to open and enlarge fractures within a hydrocarbon-bearing rock formation, usually shale [8]. The fluid consists of dilute acid, a proppant (e.g., sand) and a range of chemical additives, including surfactants, viscosity modifiers or gelling agents (polyacrylamide, guar gum) and biocides to inhibit microbial fouling $[8,13,14]$. The internal pressure of the rock formation causes water to return to the surface through the well. This water comprises both 'flow-back', i.e., returned drilling and hydraulic fluids, in addition to 'produced' water, consisting of formation brines from the hydrocarbon reservoir and extracted along with the oil and gas. The proportion of flow-back and produced water from a given well changes over time with the latter making a greater contribution $(>90 \%)$ as the asset ages (e.g., [15]). This change is accompanied by an increase in salinity and, importantly for this study, radium $[4,9,15-19]$ (see Table S1 in Supplementary Materials for selected analyses of produced water).

Radium has similar chemical properties to barium and readily co-precipitates in barium sulphate (barite), the most cost-effective way of removing radium from saline fluids [20]. The sulphate-based co-precipitation of radium isotopes in a binary system with barium salts has been investigated in numerous studies since it was first used to isolate the element, most notably by Doerner and Hoskins in 1925 [21-23]. Experimental work tends to concentrate on ${ }^{226} \mathrm{Ra}$, which is of more environmental concern than ${ }^{228}$ Ra owing to its greater abundance (reflecting the higher solubility of its precursor ${ }^{238} \mathrm{U}$, as opposed to ${ }^{232} \mathrm{Th}$ ) and much longer half-life; 1602 years compared to 5.75 years [24]. A study by Zhang et al. [20] investigated the relationship between ionic strength and ${ }^{226} \mathrm{Ra}$ recovery during barite co-precipitation using solutions containing $5 \mathrm{mM} \mathrm{Ba}^{2+}$ and varying $\mathrm{SO}_{4}{ }^{2-}$ concentrations at each ionic strength to keep the mass of barite precipitate constant. Their study concluded that an increase in salinity may improve ${ }^{226}$ Ra recovery by decreasing electrolyte activity and therefore, barite nucleation rate (diffusion-controlled growth). They postulated that a reduction in nucleation rate may enhance incorporation of radium into barite because it allows more time for lattice replacement; the latter occurring only during nucleation and crystal growth [25-29].

It has been shown that ${ }^{226} \mathrm{Ra}$ can also be removed from solution by re-crystallisation of a barite precipitate that has been left to stand [30,31]. Bosbach et al. [30] described the kinetics of ${ }^{226} \mathrm{Ra}$ incorporation into a $\mathrm{Ba}_{1-\mathrm{x}} \mathrm{Ra}_{x} \mathrm{SO}_{4}$ solid solution over the course of more than a year and found that the uptake rate dropped significantly over time. Their experiments used $2.3 \mathrm{mM}$ of pre-formed barite in $0.1 \mathrm{M} \mathrm{NaCl}$ and determined a steady state aqueous ${ }^{226} \mathrm{Ra}$ concentration after around 100 days, interpreted as approaching thermodynamic equilibrium.

The focus of this study is optimisation of ${ }^{226} \mathrm{Ra}$ recovery during barite co-precipitation by determining the minimum amount of $\mathrm{SO}_{4}{ }^{2-}$ that needs to be added to remove the maximum possible amount of radium from produced water (sulphate is the preferred reagent to use in excess under field conditions). Initial experiments employ a much lower $\mathrm{Ba}^{2+}$ concentration than that used by Zhang et al. [20], more representative of conditions found in onshore UK wells [7], and the amount of barite precipitate is allowed to vary. A comparison is made between low and high salinity $(0.3$ and $3 \mathrm{M})$, slightly acidic $(\mathrm{pH}=\sim 6)$ solutions containing $0.22 \mathrm{mM}\left(30 \mathrm{mg} / \mathrm{dm}^{3}\right) \mathrm{Ba}^{2+}$ and $\sim 100 \mathrm{~Bq} / \mathrm{dm}^{3226} \mathrm{Ra}$. These experiments are, by definition, illustrative given the very wide range of compositions shown in global analyses of produced water (Table S1 in Supplementary Materials) but nevertheless, provide a basis for more exhaustive tests. At the next stage, a kinetic experiment was undertaken to determine whether leaving the system to remove more ${ }^{226} \mathrm{Ra}$ by post-precipitation recrystallization is fast enough to be of practical use in industry. Centrifugation and ultrafiltration were used to separate the radiobarite 
precipitate from the remaining fluid; centrifugation could easily be scaled-up for use in an industrial setting. The specific activity and volume of the resulting solid were then calculated.

\section{Materials and Methods}

\subsection{Reagents}

${ }^{226} \mathrm{RaCl}_{2}$ solution was obtained from the National Physical Laboratory (NPL), UK. $\mathrm{BaCl}_{2}(99.9 \%)$ was obtained from Sigma Aldrich, $\mathrm{Na}_{2} \mathrm{SO}_{4}(99.1 \%)$ from VWR Chemicals and $\mathrm{NaCl}(>99 \%)$ from Acros Organics. Trace metal grade $\mathrm{Ba}^{2+}$ in $2 \% \mathrm{HNO}_{3}$ and scintillation cocktail were obtained from Fischer Chemical and Gold Star, respectively.

\subsection{Radium Recovery by Barite Co-Precipitation}

Two solutions $\left(2 \mathrm{dm}^{3}\right)$ were prepared at 0.3 and $3 \mathrm{M} \mathrm{NaCl}$ respectively, both with $0.22 \mathrm{mM}$ $\mathrm{Ba}^{2+}$ (using $\mathrm{BaCl}_{2}$ ) in deionised $\mathrm{H}_{2} \mathrm{O}$. Each solution was spiked with $\sim 100 \mathrm{~Bq} / \mathrm{dm}^{3226} \mathrm{Ra}$ and the $\mathrm{pH}$ adjusted to $\sim 6$ using $\mathrm{HCl}$. Aliquots of $50 \mathrm{~cm}^{3}$ were taken from each solution into separate centrifuge tubes and varying amounts of $\mathrm{SO}_{4}{ }^{2-}\left(0.1-70 \mathrm{mM}\right.$ as $\left.\mathrm{Na}_{2} \mathrm{SO}_{4}\right)$ were added to each vessel. All experiments were run in triplicate. Each vessel was centrifuged $(2 \times 20 \mathrm{~min}$ at $6000 \mathrm{rpm})$. An Amicon 8050 ultrafiltration cell under $\mathrm{N}_{2}$ pressure coupled with an Isopore membrane filter (polycarbonate, hydrophilic, $0.22 \mu \mathrm{m}, 44 \mathrm{~mm}$ diameter) was used for ultrafiltration. After separation, the samples were analysed by gamma spectrometry.

A Canberra BE2820 high-purity germanium crystal spectrometer with cryostatic cooling (CP-5SL) and carbon epoxy window was used for gamma spectrometry. Measurements for the precipitate are reported in each experiment, except where values were below the minimum detectable amount (MDA) for ${ }^{226} \mathrm{Ra}$ (MDA $=\sim 0.6 \mathrm{~Bq}$ for an 18-hour count), in which case the filtrate measurement is reported. The key peak for determination of ${ }^{226} \mathrm{Ra}$ activity was $186 \mathrm{keV}$, as the solutions contain no uranium and thus, interference from ${ }^{235} \mathrm{U}$ is negligible [32]. Count times ranged from 16,000-64,800 seconds $(18 \mathrm{~h})$ depending on sample activity. Precipitates were measured either as point sources on the Isopore membrane filter or in small $1 \mathrm{~cm}$ diameter glass vials. Filtrates were measured in $50 \mathrm{~cm}^{3}$ plastic pots. The resulting spectra were analysed using Genie 2000 V3.2 (2009) spectral analysis software, incorporating LABSOCS S573. All spectra were corrected for ambient background. International certified reference standard, IAEA-434 [33] $\left({ }^{226} \mathrm{Ra}\right.$ and $\left.{ }^{210} \mathrm{~Pb}\right)$ for solids and an aqueous standard $\left({ }^{241} \mathrm{Am},{ }^{109} \mathrm{Cd},{ }^{57} \mathrm{Co},{ }^{139} \mathrm{Ce},{ }^{51} \mathrm{Cr},{ }^{113} \mathrm{Sn},{ }^{85} \mathrm{Sr},{ }^{54} \mathrm{Mn},{ }^{137} \mathrm{Cs},{ }^{88} \mathrm{Y},{ }^{65} \mathrm{Zn}\right.$ and $\left.{ }^{60} \mathrm{Co}\right)$ supplied as $10 \mathrm{kBq} / \mathrm{g}$, by NPL (Product Code: R08-04) were used for verification. Energy calibrations were run fortnightly using a standard ${ }^{152} \mathrm{Eu}$ source to check for peak drift and consistency in raw counts.

\subsection{Kinetics of Radium Recovery by Barite Post-Precipitation}

Reaction kinetics were investigated under similar conditions to those above. Two $50 \mathrm{~cm}^{3}$ solutions were prepared at 0.3 and $3 \mathrm{M} \mathrm{NaCl}$ with $0.22 \mathrm{mM} \mathrm{Ba}^{2+}$ (using $\mathrm{BaCl}_{2}$ ) in deionised $\mathrm{H}_{2} \mathrm{O}$. Each solution was spiked with $\sim 100 \mathrm{~Bq} / \mathrm{dm}^{3226} \mathrm{Ra}$ and $\mathrm{pH}$ adjusted to $\sim 6$ using $\mathrm{HCl}$. Sulphate $(1.5$ and $15 \mathrm{mM}$ as $\mathrm{Na}_{2} \mathrm{SO}_{4}$ ) was added to the 0.3 and $3 \mathrm{M}$ solutions, respectively. Each vessel was centrifuged $(2 \times 20 \mathrm{~min}$ at $6000 \mathrm{rpm}$ ) for experimental consistency, although separation was not required. Further ${ }^{226} \mathrm{Ra}$ $\left(20 \mathrm{kBq} / \mathrm{dm}^{3}\right)$ was then added and aliquots of $0.25 \mathrm{~cm}^{3}$ were taken at increasing time intervals from $30 \mathrm{~min}$ to 14 days. A larger quantity of ${ }^{226} \mathrm{Ra}$ was required so that small differences in activity between short time intervals could be determined accurately. The ${ }^{226} \mathrm{Ra}$ activity in each aliquot was then analysed by liquid scintillation counting (LSC). Each $0.25 \mathrm{~cm}^{3}$ aliquot was added to $10 \mathrm{~cm}^{3}$ of scintillation cocktail in a standard plastic LSC vial. The samples were sealed in the vial and left for 4 weeks so that ${ }^{226} \mathrm{Ra}$ could reach secular equilibrium with ${ }^{222} \mathrm{Rn}$. A Packard 2100 TR LSC was used for all measurements. A total count of $\alpha$-emissions from ${ }^{226} \mathrm{Ra}$ as well as ${ }^{222} \mathrm{Rn}$ and ${ }^{218} \mathrm{Po}$ (daughters of ${ }^{226} \mathrm{Ra}$ with peaks that cannot be de-convoluted) was used to quantify ${ }^{226} \mathrm{Ra}$ [30] (counting window: $4.5-8 \mathrm{MeV})$. All raw counts were subject to a background correction. 


\subsection{Mineralogical Analysis}

A Carl Zeiss (Leo) 1530 variable pressure high-resolution field emission gun scanning electron microscope (SEM) was used to assess the crystal form of precipitated radiobarite. The instrument includes an energy dispersive X-ray system for chemical analysis using an Oxford Instruments X-Max $80 \mathrm{~mm}^{2}$ detector. The samples were studied under high vacuum ( $\left.<1 \mathrm{~Pa}\right)$. Back-scattered electron (BSE) images and energy dispersive X-ray (EDX) spectra were recorded using a $15 \mathrm{kV}$ electron beam voltage and fast scan speeds, as required, to limit sample charging. Samples were coated with an $\mathrm{Au} / \mathrm{Pd}$ alloy to improve image quality.

\section{Results}

\subsection{Radium Recovery by Barite Co-Precipitation}

Initial experiments were conducted to determine the amount of $\mathrm{SO}_{4}{ }^{2-}$ required to remove the 'maximum' amount of ${ }^{226} \mathrm{Ra}$ by barite co-precipitation at 0.3 and $3 \mathrm{M} \mathrm{NaCl}$. The barium concentration chosen was $0.22 \mathrm{mM}\left(30 \mathrm{mg} / \mathrm{dm}^{3}\right)$. This is a low concentration when compared to the brines encountered in the USA, where values in the Marcellus Shale can exceed $20 \mathrm{~g} / \mathrm{dm}^{3}$ [18]; the rationale being that significant sulphate addition is then needed to induce precipitation. As more $\mathrm{SO}_{4}{ }^{2-}$ was added, an increase in ${ }^{226} \mathrm{Ra}$ recovery was observed until a maximum of $\geq 90 \%$ was achieved at each ionic strength. At $0.3 \mathrm{M} \mathrm{NaCl}, \sim 1.5 \mathrm{mM} \mathrm{SO}_{4}{ }^{2-}$ was required to reach this maximum (Figure $1 \mathrm{~A}$ ) whereas at $3 \mathrm{M}, \sim 15 \mathrm{mM} \mathrm{SO}_{4}{ }^{2-}$ was required, showing the relationship to be linear (Figure 1B; Table S2 for the full data set).
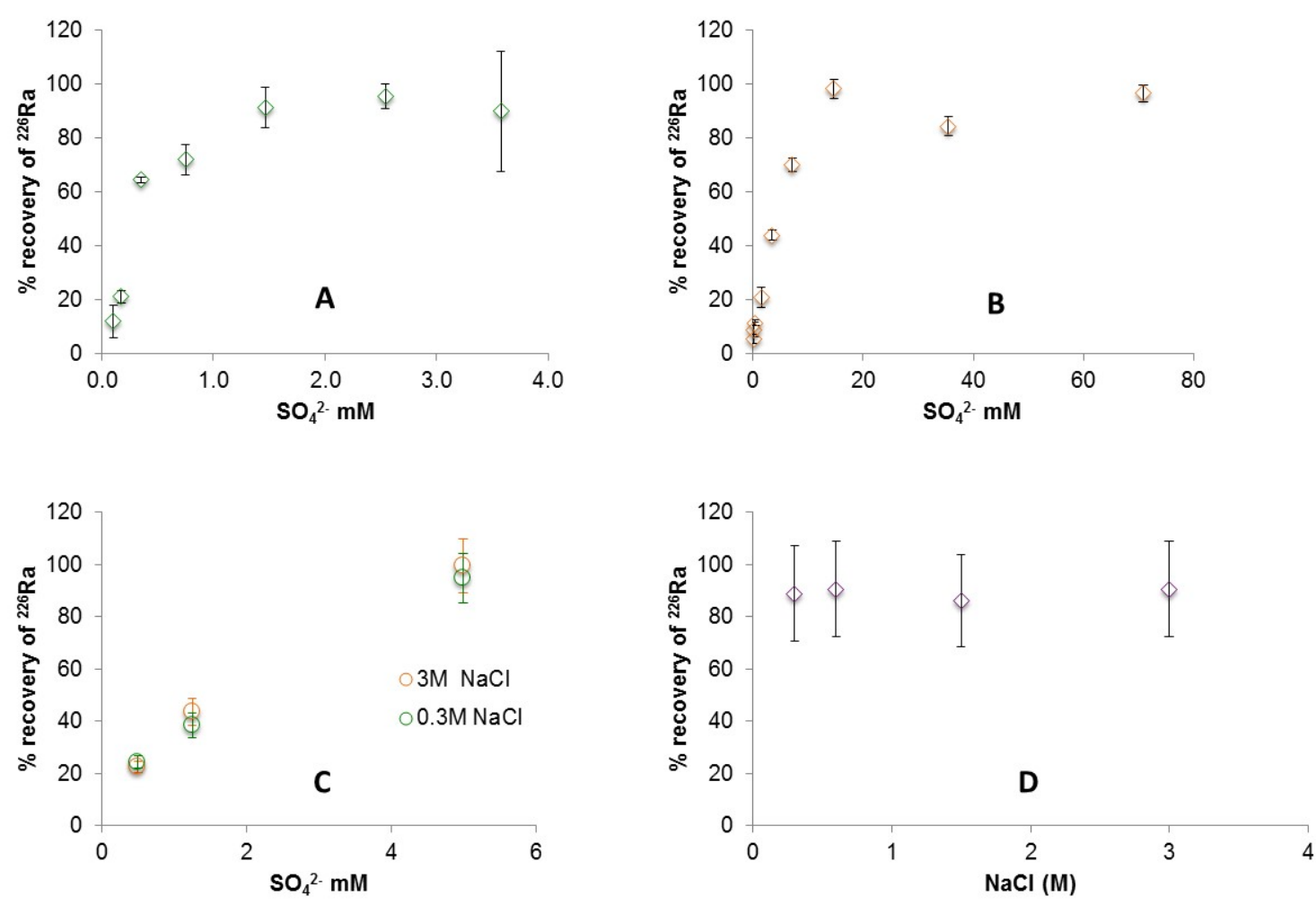

Figure 1. ${ }^{226} \mathrm{Ra}$ recovery by barite co-precipitation. (A) $0.3 \mathrm{M} \mathrm{NaCl}$ with $0.22 \mathrm{mM} \mathrm{Ba}^{2+}$ and varying $\mathrm{SO}_{4}{ }^{2-}$; (B) $3 \mathrm{M} \mathrm{NaCl}$ with $0.22 \mathrm{mM} \mathrm{Ba}^{2+}$ and varying $\mathrm{SO}_{4}{ }^{2-}$; (C) 0.3 and $3 \mathrm{M} \mathrm{NaCl}^{2}$ with $5 \mathrm{mM} \mathrm{Ba}^{2+}$ and varying $\mathrm{SO}_{4}{ }^{2-}$; (D) $0.3,0.6,1.5$ and $3 \mathrm{M} \mathrm{NaCl}$ with $20 \mathrm{mM} \mathrm{Ba}^{2+}$ and $\mathrm{SO}_{4}{ }^{2-}$.

The radiobarite crystals formed in the optimised co-precipitation process were imaged by scanning electron microscope to compare crystal morphology. At $0.3 \mathrm{M} \mathrm{NaCl}$ the crystals are of uniform size and euhedral (Figure 2A), whereas in the more saline solution the crystals are subhedral, generally 
larger and show poorer crystal form (Figure 2B). The effect that salinity has on both the co-precipitation process and crystal form will obviously influence settling behaviour during radium removal.
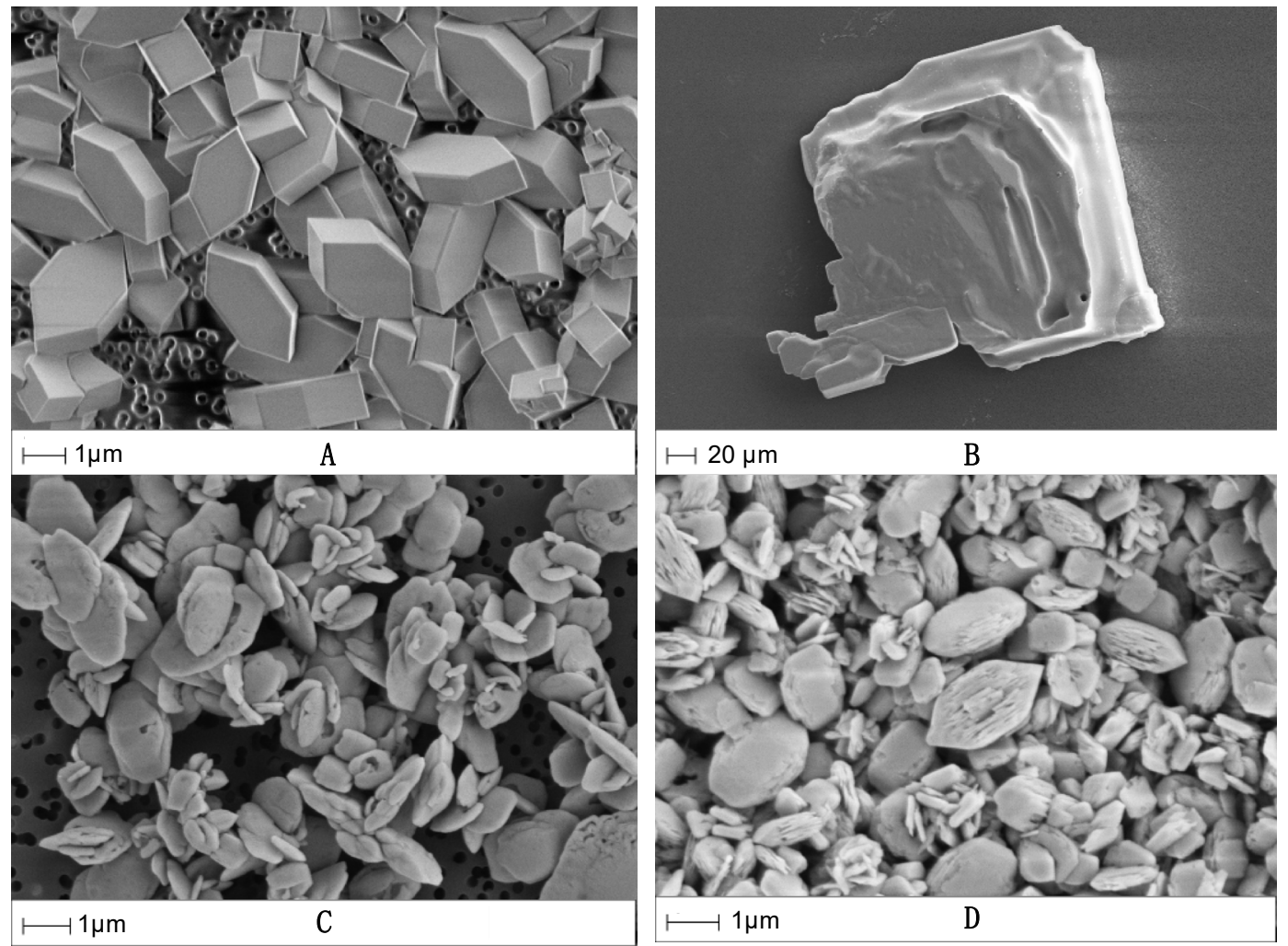

Figure 2. High-resolution SEM images of the radiobarite crystals formed in 0.3 and $3 \mathrm{M} \mathrm{NaCl}$ solutions at different initial $\mathrm{Ba}^{2+}$ concentrations. (A) $0.3 \mathrm{M} \mathrm{NaCl}$ with $0.22 \mathrm{mM} \mathrm{Ba}^{2+}$ and $1.5 \mathrm{mM} \mathrm{SO}_{4}{ }^{2-}$; (B) $3 \mathrm{M}$ $\mathrm{NaCl}$ with $0.22 \mathrm{mM} \mathrm{Ba}^{2+}$ and $15 \mathrm{mM} \mathrm{SO}_{4}{ }^{2-}$; (C) $0.3 \mathrm{M} \mathrm{NaCl}$ with $5 \mathrm{mM} \mathrm{Ba}^{2+}$ and $0.5 \mathrm{mM} \mathrm{SO}_{4}{ }^{2-}$; (D) $3 \mathrm{M} \mathrm{NaCl}$ with $5 \mathrm{mM} \mathrm{Ba}^{2+}$ and $0.5 \mathrm{mM} \mathrm{SO}_{4}{ }^{2-}$.

Experiments were conducted using higher concentrations of $\mathrm{Ba}^{2+}(5 \mathrm{mM}$, as used by Zhang et al. [20]) for comparison. In this study, however, a range of $\mathrm{SO}_{4}{ }^{2-}$ concentrations $(0.5$, 1.25 and $5 \mathrm{mM}$ ) was added and the amount of barite precipitate was not kept constant. The experiments were conducted in $\mathrm{pH} \sim 6$ solutions at 0.3 and $3 \mathrm{M} \mathrm{NaCl}$. Figure $1 \mathrm{C}$ indicates that similar amounts of ${ }^{226} \mathrm{Ra}$ are removed, irrespective of salinity, when adding the same amount of $\mathrm{SO}_{4}{ }^{2-}$ (Table S3 for the full data set). SEM imaging (Figure 2C,D) indicates that the radiobarite crystals formed are uniform in size and overall, subhedral in form. These observations show that the initial concentration of $\mathrm{Ba}^{2+}$ also has a major effect on crystal form. Recovery of ${ }^{226} \mathrm{Ra}$ at both salinities when using $5 \mathrm{mM} \mathrm{SO}_{4}{ }^{2-}$ was comparable to the maximum determined in the initial experiments.

Ultrafiltration was required to separate the solid and liquid phase, as the quantity of radiobarite was too small for centrifugation to be effective; this would be impracticable in an industrial setting. Instead, the reagent quantities could be increased to a level appropriate for centrifugation. Experiments using higher concentrations of both $\mathrm{Ba}^{2+}$ and $\mathrm{SO}_{4}{ }^{2-}(20 \mathrm{mM})$ were conducted in $0.3,0.6,1.5$ and $3 \mathrm{M}$ $\mathrm{NaCl}$. Figure 1D shows that the levels of ${ }^{226}$ Ra recovery obtained (mean $=89 \%$ ) are comparable. At these reagent concentrations, therefore, ${ }^{226}$ Ra recovery appears to be independent of ionic strength, a useful finding for practical field applications.

\subsection{Kinetics of Radium Recovery by Barite Recrystallization Post-Precipitation}

Following the optimised co-precipitation step, more ${ }^{226} \mathrm{Ra}$ was added and its aqueous concentration monitored over time in 0.3 and $3 \mathrm{M} \mathrm{NaCl}$, respectively, to determine the rate at which residual ${ }^{226} \mathrm{Ra}$ in 
solution could be removed from solution by recrystallization of the precipitate. Measurements were restricted to 14 days, as in industry it is not feasible to store large volumes of radioactive fluid on site for longer periods (e.g., [15]). Figure 3 shows a pattern of diminishing returns in ${ }^{226}$ Ra recovery by post-precipitation at each $\mathrm{NaCl}$ concentration with the rate rapid in the first $24 \mathrm{~h}$ then dropping significantly over the 14-day period.

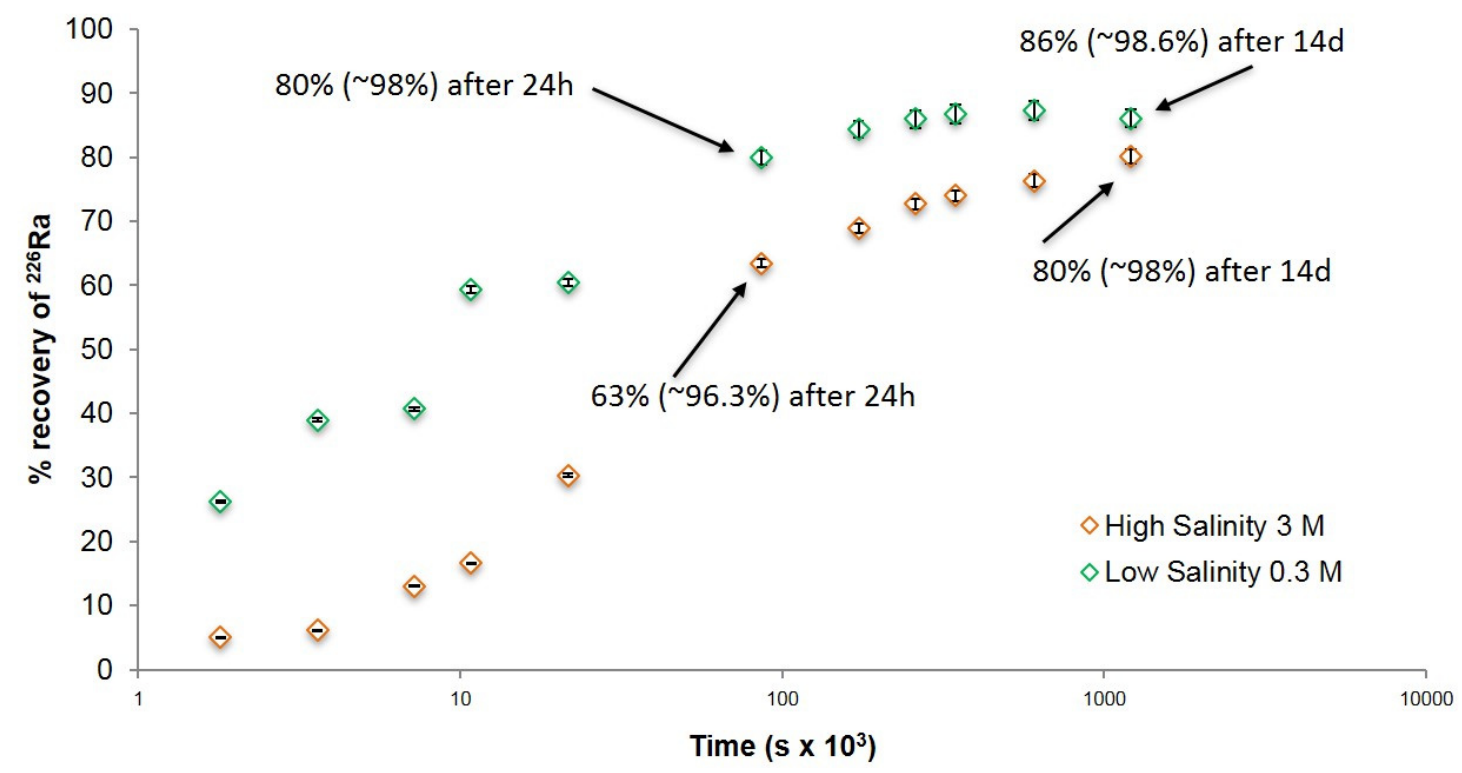

Figure $3 .{ }^{226} \mathrm{Ra}$ recovery by barite post-precipitation. Low Salinity: $0.3 \mathrm{M} \mathrm{NaCl}$ with $0.22 \mathrm{mM}$ barite $\left(0.22 \mathrm{mM} \mathrm{Ba}^{2+}+1.5 \mathrm{mM} \mathrm{SO}_{4}{ }^{2-}\right)$; High Salinity: $3 \mathrm{M} \mathrm{NaCl}$ with $0.22 \mathrm{mM}$ barite $\left(0.22 \mathrm{mM} \mathrm{Ba}^{2+}+15 \mathrm{mM}\right.$ $\mathrm{SO}_{4}{ }^{2-}$ ). The values in parentheses show overall removal (co-precipitation (maximum of $90 \%$ ) plus post-precipitation uptake). $2 \sigma$ error is based on counting statistics only.

The rate of ${ }^{226} \mathrm{Ra}$ recovery at $0.3 \mathrm{M} \mathrm{NaCl}$ (Figure 3; Low Salinity) is faster than at $3 \mathrm{M}$ (Figure 3; High Salinity), the difference being more pronounced in the first $24 \mathrm{~h}$. Residual recovery at $24 \mathrm{~h}$ was $80 \%$ and $63 \%$ for 0.3 and $3 \mathrm{M} \mathrm{NaCl}$, respectively. Although the difference appears marginal, corresponding to overall recovery (from co-precipitation plus recrystallization) of $98 \%$, as opposed to $96 \%$, it has to be viewed in the context of the extremely low discharge limits imposed by national regulators. After 14 days, $>80 \%$ of the residual ${ }^{226}$ Ra was recovered, slightly more ${ }^{226}$ Ra being removed under dilute conditions. Co-precipitation, together with 14 days of recrystallization, therefore, yields an overall recovery of $\sim 98 \%$ (see Table S4 for the full data set).

\section{Discussion}

Radium-226 recovery by barite co-precipitation has been optimised for solutions with a relatively low initial barium concentration; its efficiency is significantly affected by salinity. At $0.22 \mathrm{mM} \mathrm{Ba}{ }^{2+}$, higher salinity systems require substantially more $\mathrm{SO}_{4}{ }^{2-}$ to achieve a maximum ${ }^{226} \mathrm{Ra}$ recovery of $\sim 90 \%$ (Figure $1 \mathrm{~A}, \mathrm{~B}$ ). This is likely due to the activity of the $\mathrm{Ba}^{2+}$ and $\mathrm{SO}_{4}{ }^{2-}$ ions in solution being reduced by competing ions $[30,31,34,35]$; reduced precipitation of barite naturally resulting in reduced uptake of ${ }^{226} \mathrm{Ra}$.

The opposite effect can be observed when a large excess of $\mathrm{Ba}^{2+}(5 \mathrm{mM})$ is present (Figure $\left.1 \mathrm{C}\right)$. The same observation was made by Zhang et al. [20] and can be explained by a decrease in nucleation rate resulting in more lattice replacement of $\mathrm{Ba}^{2+}$ by radium. These authors kept the amount of barite precipitate constant across the range of ionic strengths; however, in this study, the amount of barite precipitate was allowed to vary. Even so, at higher ionic strengths, the effects appear large enough to counteract the smaller quantity of barite that is precipitated, resulting in similar recovery of ${ }^{226} \mathrm{Ra}$ 
at the same salinity. In all experiments, at both 0.22 and $5 \mathrm{mM} \mathrm{Ba}^{2+}, \sim 15 \mathrm{mM} \mathrm{SO}_{4}{ }^{2-}$ is sufficient to recover the maximum amount of ${ }^{226} \mathrm{Ra}$ feasible in one co-precipitation step.

Using $20 \mathrm{mM}$ of both $\mathrm{Ba}^{2+}$ and $\mathrm{SO}_{4}{ }^{2-}$, recovery of ${ }^{226} \mathrm{Ra}$ from these fluids by barite co-precipitation was of comparable efficiency at $\sim 89 \%$ (Figure 1D). These reagent concentrations make centrifugation more practicable and would contribute towards masking the effects of other constituents on the radium recovery process in a 'real' produced water, though, of course, caution is needed in extrapolating the laboratory data. For example, the presence of strontium, which was not considered here, may suppress the uptake of radium from solution by modifying the composition of the solid-solution towards the celestite $\left(\mathrm{SrSO}_{4}\right)$ end member [34,36], not all of the sulphate added would be available for barite precipitation and addition of soluble salts will increase barite solubility [34]. Other factors not considered in this paper, such as the presence of organic contaminants (e.g., [37]) might well render centrifugation impractical and outweigh radiological concerns. Cost may also be a consideration militating against overdosing the system with excess reagent.

If $>90 \%$ radium recovery is sought, a further co-precipitation step of similar efficiency, may allow the target of $\sim 99 \%$ removal to be achieved; this would require additional $\mathrm{Ba}^{2+}$ and $\mathrm{SO}_{4}{ }^{2-}$. Alternatively, the system could be left to remove more radium by barite recrystallization over time. However, this process is much slower than co-precipitation. It would take $>7$ days to gain $>80 \%$ recovery of the residual radium from the first co-precipitation step $\left(\sim 98 \%{ }^{226}\right.$ Ra recovery overall; Figure 3$)$. Increasing the amount of barite present may increase the rate of radium recovery but would not approach the rate that could be achieved by further co-precipitation $[30,38]$.

The kinetic experiment (Figure 3) shows a pattern of diminishing returns on the rate of ${ }^{226} \mathrm{Ra}$ recovery. The rate is relatively fast in the first $24 \mathrm{~h}$, then decreases over 14 days at each ionic strength, in agreement with the findings of Bosbach et al. [30]. The slower rate of radium recovery at $3 \mathrm{M} \mathrm{NaCl}$ could again be due to an increase in barite solubility $[34,35]$. Crystal form might also be a contributing factor (Figure 2A,B). The smaller, uniform crystals in the more dilute system would provide a larger surface area for adsorption of ${ }^{226} \mathrm{Ra}$. Although radium uptake has been shown to proceed significantly beyond pure surface adsorption processes to lattice incorporation over timescales of a year or more (e.g., [30]), it is likely to be surface dominated on the shorter periods ( $\leq 14$ days) considered here.

Geochemical modelling was conducted in order to determine ion activities, barite saturation indices, the mass of precipitated barite and theoretical radium recovery. PHREEQC [39] was used in conjunction with the Specific Ion Interaction Theory (SIT) database [40,41], which is applicable over the range of ionic strengths studied. $\mathrm{Zhu}$ [42] describes a semi-empirical model of the $\mathrm{Ba}_{1-\mathrm{x}} \mathrm{Ra}_{\mathrm{x}} \mathrm{SO}_{4}$ solid solution, which could be used to predict radium recovery. This study applied the model using the experimentally validated dimensionless Guggenheim interaction parameter, $\mathrm{a}_{0}=1 \pm 0.4$, as derived by Vinograd et al. [38] (Tables S5 and S6 for PHREEQC output).

Barite saturation indices ( $\mathrm{SI}=\log$ ion activity product/solubility product) are significantly reduced in all experiments at higher salinity due to a reduction in $\mathrm{Ba}^{2+}$ and $\mathrm{SO}_{4}{ }^{2-}$ ion activities. Under optimised co-precipitation conditions $\left(0.22 \mathrm{mM} \mathrm{Ba}^{2+}\right)$, similar barite saturation indices of 2.2 and 2.4 were observed at 0.3 and $3 \mathrm{M} \mathrm{NaCl}$, respectively. This shows that radium recovery is largely dependent on the amount of barite that can precipitate, as suggested above. At $5 \mathrm{mM} \mathrm{Ba}^{2+}$ the barite saturation indices are $>2.2$, so it may be expected that the maximum removal of radium would be easily achieved in these experiments. However, at 0.5 and $1.25 \mathrm{mM} \mathrm{SO}_{4}{ }^{2-},<50 \%$ of the ${ }^{226} \mathrm{Ra}$ present in solution co-precipitated with the barite. Therefore, barite saturation index alone cannot be relied upon to predict the amount of radium that will be recovered from solution; the initial $\mathrm{Ba}^{2+}$ concentration must also be considered. It appears that, at low concentrations of $\mathrm{Ba}^{2+}$, a lower barite saturation index is required to reach the maximum radium recovery determined. Observations made by Kowacz et al. [43] and Piana et al. [44] provide a possible explanation. They suggest that de-solvation of $\mathrm{Ba}^{2+}$ and of the barite surface is a rate-limiting step in barite crystal growth. The rate of crystal growth may have a significant effect therefore, on the amount of lattice replacement that can occur [20]. 
The theoretical radium recovery was calculated and compared to experimental values from the co-precipitation experiments (Figure 4). At $0.22 \mathrm{mM} \mathrm{Ba}^{2+}$, experimental values are substantially lower than the theoretical predictions at intermediate barite saturation (Figure $4 \mathrm{~A}, \mathrm{~B})$. The model appears to be more accurate at the extremes of barite saturation $(<0.5$ and $>2)$ where either very little or maximum radium is recovered. In contrast, at $5 \mathrm{mM} \mathrm{Ba}^{2+}$ (Figure $4 \mathrm{C}, \mathrm{D}$ ), the model tends to underestimate radium recovery at the two lower barite saturation indices. The main drawback with the model is that it assumes complete thermodynamic equilibrium [30,31,38]; thus, the discrepancy between the theoretical and experimental results could be interpreted as partial equilibrium of the barite crystals.
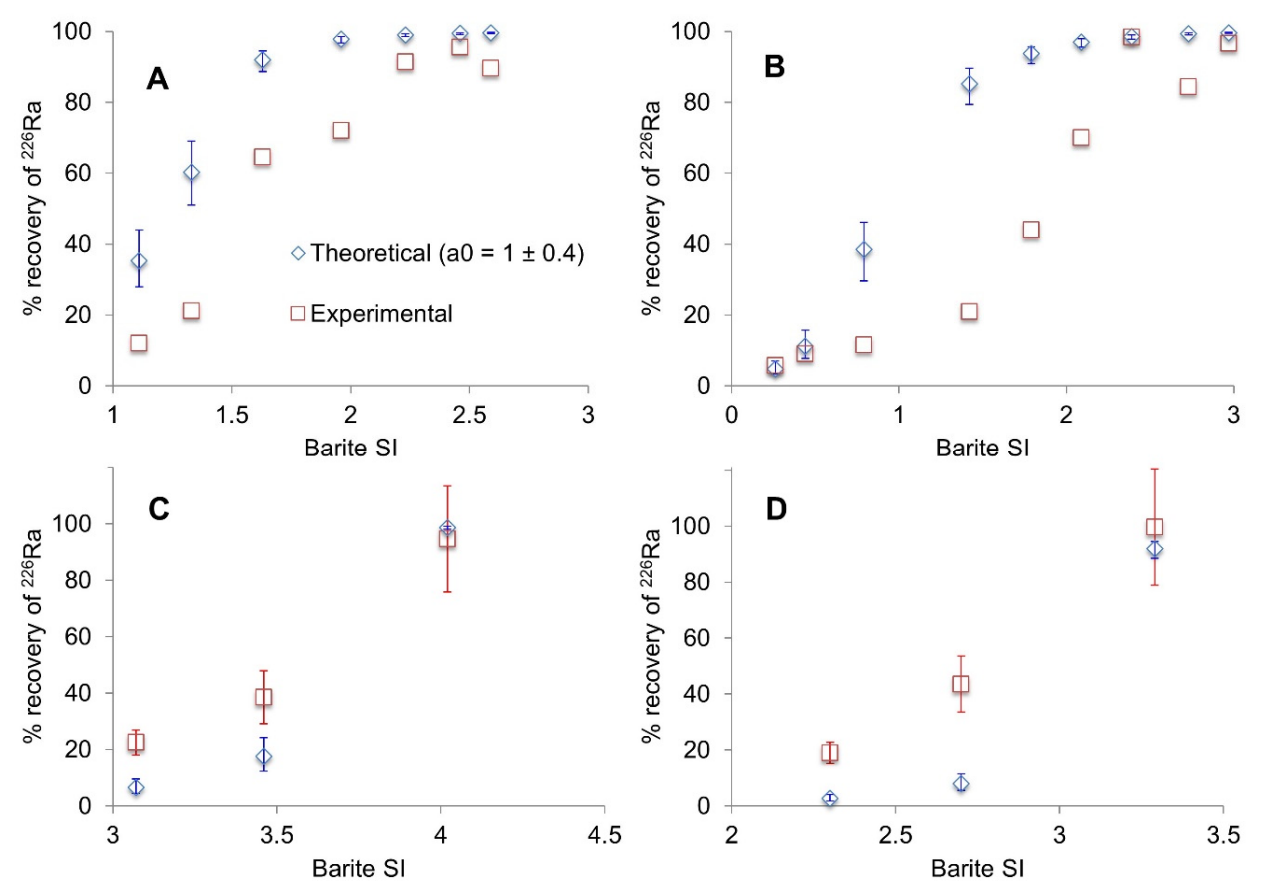

Figure 4. Theoretical vs. experimentally determined $\%{ }^{226}$ Ra recovery. (A) $0.3 \mathrm{M} \mathrm{NaCl}$ with $0.22 \mathrm{mM}$ $\mathrm{Ba}^{2+}$ and varying $\mathrm{SO}_{4}{ }^{2-}$; (B) $3 \mathrm{M} \mathrm{NaCl}$ with $0.22 \mathrm{mM} \mathrm{Ba}^{2+}$ and varying $\mathrm{SO}_{4}{ }^{2-}$; (C) $0.3 \mathrm{M} \mathrm{NaCl}$ with $5 \mathrm{mM} \mathrm{Ba}^{2+}$ and varying $\mathrm{SO}_{4}{ }^{2-}$; (D) $3 \mathrm{M} \mathrm{NaCl}$ with $5 \mathrm{mM} \mathrm{Ba}^{2+}$ and varying $\mathrm{SO}_{4}{ }^{2-} .2 \sigma$ error based on counting statistics only. SI-Saturation Index. Theoretical values are based on $\mathrm{a}_{0}=1 \pm 0.4$.

The model does not explicitly consider the process of co-precipitation; therefore, it should be more applicable when recrystallization has taken place, provided that the crystals are fully equilibrated with the solution. This is unlikely over 14 days, as $>100$ days are believed to be required to achieve thermodynamic equilibrium $[30,38]$. Such a timescale would almost certainly not be viable in the field. The model predicts $98 \%-99 \%$ radium recovery at thermodynamic equilibrium at each ionic strength whereas recoveries of only $86 \%$ at $0.3 \mathrm{M}$ and $80 \%$ at $3 \mathrm{M} \mathrm{NaCl}$, were reached over 14 days, again suggesting these systems were not at thermodynamic equilibrium.

On the basis of these experiments, approximately $10 \%$ of the initial ${ }^{226}$ Ra may remain in solution after a single co-precipitation step. The national exemption limit for aqueous radioactive waste discharge in the UK [10] is $0.01 \mathrm{~Bq} / \mathrm{dm}^{3}$. Thus, for some produced waters reported from the Marcellus Shale $[4,17]\left({ }^{226} \mathrm{Ra} \leq 629 \mathrm{~Bq} / \mathrm{dm}^{3}\right)$ and all of those reported to date in the UK's Bowland Shale [9] (14-90 Bq/ $\left.\mathrm{dm}^{3}\right), \sim 90 \%$ recovery, while highly effective, would not be sufficient. First, compliance would require multiple co-precipitation steps or an extended post-precipitation recrystallization period to achieve $>99.9 \%{ }^{226}$ Ra removal, which may not be feasible in practice [45-49]. Second, measurement of whether or not the compliance level has been reached would require highly sensitive radiometric analysis by alpha spectrometry, which is extremely challenging in a field setting [12].

The resulting radiobarite waste also needs to be considered, as the majority of the initial radium present in the produced water would be sequestered in this phase. According to the model, the 
optimised co-precipitation experiments would result in $0.22 \mathrm{mM}\left(51 \mathrm{mg} / \mathrm{dm}^{3}\right)$ of barite precipitate at $0.3-3 \mathrm{M} \mathrm{NaCl}$, though much more saline waters are known $[4,17,18]$. With a typical initial aqueous ${ }^{226} \mathrm{Ra}$ concentration of $\sim 100 \mathrm{~Bq} / \mathrm{dm}^{3}$, recovery of $\sim 90 \%$ would produce barite containing $\sim 90 \mathrm{~Bq}{ }^{226} \mathrm{Ra}$ with a specific activity of $\sim 1.75 \mathrm{kBq} / \mathrm{g}$. Although the specific activity is high, the volume and therefore, total activity of the waste will be relatively low. Increasing the amount of reagent would reduce the specific activity but increase the waste volume. For example, $20 \mathrm{mM}\left(4.7 \mathrm{~g} / \mathrm{dm}^{3}\right)$ of barite precipitate would yield a specific activity of $\sim 19.3 \mathrm{~Bq} / \mathrm{g}$ at $\sim 90 \%{ }^{226}$ Ra recovery. A detailed discussion of the risk associated with alternative waste treatment methods would necessarily be site-specific and is beyond the scope of the current paper. A preliminary attempt to assess the health risks posed by radium-rich sludge contained in flow-back water impoundments in Pennsylvania, USA [49] did not compare alternative routes but could form a useful case study. In practice, a balance will need to be struck to yield a waste form which can be both handled safely and is relatively inexpensive to dispose.

\section{Conclusions}

Saline produced waters from unconventional gas extraction in the United States and elsewhere are typically enriched in radium isotopes posing an occupational and environmental challenge. Experience onshore in the UK, albeit limited to date, suggests similar problems would arise if the technology were to be pursued at an industrial scale. If re-injection is not an option, as seems likely, the fluid would need to be decontaminated prior to surface discharge. Co-precipitation of radium in barite is a cost-effective method for creating a less problematic solid waste form, provided the process can be controlled. In this work, radium recovery of $\sim 90 \%$ has been achieved for simulant produced waters containing $100 \mathrm{~Bq} / \mathrm{dm}^{3226} \mathrm{Ra}$ using a single, optimised co-precipitation step. However, higher salinity solutions required substantially more reagent to achieve the same recovery. If $>90 \%$ radium removal is sought, multiple co-precipitation steps provide a much faster alternative than post-precipitation recrystallization of the barite solid phase. The resulting solid waste has a relatively high specific radium activity but a much smaller volume, which represents a less intractable disposal problem for site operators than large volumes of radium-contaminated fluid.

Supplementary Materials: The following are available online at http://www.mdpi.com/2075-163X/10/3/278/s1, Table S1: Characterisation of production water from hydraulic fracturing operations; Table S2: ${ }^{226}$ Ra recovery by co-precipitation at 0.3 and $3 \mathrm{M} \mathrm{NaCl}$ (all $0.22 \mathrm{mM} \mathrm{Ba}$ ); Table S3: ${ }^{226} \mathrm{Ra}$ recovery by co-precipitation at 0.3 and $3 \mathrm{M} \mathrm{NaCl}$ (all $5 \mathrm{mM} \mathrm{Ba}$ ); Table S4: ${ }^{226} \mathrm{Ra}$ recovery by post-precipitation at 0.3 and $3 \mathrm{M} \mathrm{NaCl}$ (all $0.22 \mathrm{mM} \mathrm{Ba}$ ); Table S5: PHREEQC output for ${ }^{226}$ Ra recovery by co-precipitation at 0.3 and $3 \mathrm{M} \mathrm{NaCl}$ (all $0.22 \mathrm{mM}$ Ba); Table S6: PHREEQC output for ${ }^{226} \mathrm{Ra}$ recovery by co-precipitation at 0.3 and $3 \mathrm{M} \mathrm{NaCl}$ (all $5 \mathrm{mM} \mathrm{Ba}$ ).

Author Contributions: Conceptualisation, methodology, writing-review and editing, J.G. and D.R.; formal analysis, investigation, original draft preparation, J.G.; supervision, project administration, funding acquisition, D.R. All authors have read and agreed to the published version of the manuscript.

Funding: This research was part-funded by Aurora Health Physics, grant number AHP/RPA/LOU/xxJUN13.

Acknowledgments: The authors would like to thank Dirk Bosbach, Victor Vinograd and colleagues from the Institute for Nuclear Waste Disposal at Forschungszentrum Jülich for guidance with the modelling study. We would also like to thank Matthew Isaacs and James Holt for their assistance with the experiments.

Conflicts of Interest: The authors declare no conflict of interest; this project was undertaken and completed during J.G.'s PhD studentship. The part-funder had no role in the design of the study; in the collection, analysis or interpretation of data; in the writing of the manuscript, or in the decision to publish the results.

\section{References}

1. Elster, J.; Geitel, H. Über die radioaktive Substanz, deren Emanation in der Bodenluft und der Atmosphäre enthalten ist. Phys. Z. 1904, 5, 321-325.

2. Schmidt, H.W.; Kurz, K. Natural radioactive substances in thermal brines. Phys. Z. 1906, 7, $213-224$.

3. Thompson, H. Fracking boom spurs environmental audit. Nature 2012, 485, 556-557. [CrossRef] [PubMed] 
4. Shih, J.-S.; Saiers, J.E.; Anisfeld, S.C.; Chu, Z.; Muehlenbachs, L.A.; Olmstead, S.M. Characterization and analysis of liquid waste from Marcellus Shale gas development. Environ. Sci. Technol. 2015, 49, 9557-9565. [CrossRef]

5. Heaton, B.; Lambley, J. TENORM in the oil, gas and mineral mining industry. Appl. Radiat. Isot. 1995, 46, 577-581. [CrossRef]

6. Worden, R.H.; Manning, D.A.C.; Lythgoe, P.R. The origin and production geochemistry of radioactive lead $\left({ }^{210} \mathrm{~Pb}\right)$ in NORM-contaminated formation waters. J. Geochem. Explor. 2000, 70, 695-699. [CrossRef]

7. Garner, J.; Cairns, J.; Read, D. NORM in the East Midlands' oil and gas producing region of the UK. J. Envrion. Radioact. 2015, 150, 49-56. [CrossRef]

8. Cooke, C.E., Jr. Hydraulic Fracturing Method. U.S. Patent US3888311A, 10 June 1975.

9. Environment Agency. Shale Gas North West-Monitoring of Flowback Water; Environment Agency: Bristol, UK, 2011.

10. Her Majesty's Stationery Office. The Environmental Permitting (England and Wales) Regulations; UK Statutory Instruments, No. 1154; Her Majesty's Stationery Office: London, UK, 2016.

11. U.S. Nuclear Regulatory Commission (NRC). Limits for Industrial Wastewater Discharge. Available online: https://www.nrc.gov/waste.html (accessed on 31 January 2020).

12. Maxwell, S.L.; Culligan, B.K.; Warren, R.A.; McAlister, D.R. Rapid method for the determination of ${ }^{226}$ Ra in hydraulic fracturing wastewater samples. J. Radioanal. Nucl. Chem. 2016, 309, 1333-1340. [CrossRef]

13. Haluszczak, L.O.; Rose, A.W.; Kump, L.R. Geochemical evaluation of flowback brine from Marcellus gas wells in Pennsylvania, USA. Appl. Geochem. 2013, 28, 55-61. [CrossRef]

14. Elliott, E.G.; Ettinger, A.S.; Leaderer, B.P.; Bracken, M.B.; Deziel, N.C. A systematic evaluation of chemicals in hydraulic-fracturing fluids and wastewater for reproductive and developmental toxicity. J. Expo. Sci. Environ. Epidemiol. 2016, 27, 90-99. [CrossRef]

15. Kondash, A.J.; Albright, E.; Vengosh, A. Quantity of flowback and produced waters from unconventional oil and gas exploration. Sci. Total Environ. 2017, 574, 314-321. [CrossRef] [PubMed]

16. Lester, Y.; Ferrer, I.; Thurman, E.M.; Sitterley, K.A.; Korak, J.A.; Aiken, G.; Linden, K.G. Characterization of hydraulic fracturing flowback water in Colorado: Implications for water treatment. Sci. Total Environ. 2015, 512-513, 637-644. [CrossRef] [PubMed]

17. Rowan, E.L.; Engle, M.A.; Kirby, C.S.; Kraemer, T.F. Radium Content of Oil- and Gas-Field Produced Waters in the Northern Appalachian Basin (USA)_Summary and Discussion of Data; U.S. Geological Survey Scientific Investigations Report 2011-5135; USGS: Reston, VA, USA, 2011; 31p.

18. Rowan, E.L.; Engle, M.A.; Kraemer, T.F.; Schroeder, K.T.; Hammack, R.W.; Doughten, M.W. Geochemical and isotopic evolution of water produced from Middle Devonian Marcellus shale gas wells, Appalachian basin, Pennsylvania. AAPG Bull. 2015, 99, 181-206. [CrossRef]

19. Blondes, M.S.; Gans, K.D.; Engle, M.A.; Kharaka, Y.K.; Reidy, M.E.; Saraswathula, V.; Thordsen, J.J.; Rowan, E.L.; Morrissey, E.A. U.S. Geological Survey National Produced Waters Geochemical Database; ver. 2.3; U.S. Geological Survey Data Release; USGS: Reston, VA, USA, 2018. [CrossRef]

20. Zhang, T.; Gregory, K.; Hammack, R.W.; Vidic, R.D. Co-precipitation of radium with barium and strontium sulfate and its impact on the fate of radium during treatment of produced water from unconventional gas extraction. Environ. Sci. Technol. 2014, 48, 4596-4603. [CrossRef] [PubMed]

21. Doerner, H.A.; Hoskins, W.M. Coprecipitation of radium with barium sulfates. J. Am. Chem. Soc. 1925, 47, 662-675. [CrossRef]

22. Gordon, L.; Rowley, K. Coprecipitation of radium with barium sulfate. Anal. Chem. 1957, $29,34-37$. [CrossRef]

23. Langmuir, D.; Riese, A.C. The thermodynamic properties of radium. Geochim. Cosmochim. Acta 1985, 49, 1573-1601. [CrossRef]

24. Choppin, G.; Liljenzin, J.-O.; Rydberg, J.; Ekberg, C. Radiochemistry and Nuclear Chemistry, 4th ed.; Academic Press: Cambridge, MA, USA, 2013.

25. Anderson, G.M.; Crerar, D.A. Thermodynamics of Geochemistry: The Equilibrium Model, 1st ed.; Oxford Univesity Press: Oxford, UK, 1993.

26. Risthaus, P.; Bosbach, D.; Becker, U.; Putnis, A. Barite scale formation and dissolution at high ionic strength studied with atomic force microscopy. Colloids Surf. 2001, 191, 201-214. [CrossRef] 
27. Fernandez-Diaz, L.; Putnis, A.; Cumberbatch, J. Barite nucleation kinetics and the effects of additives. Eur. J. Mineral. 1990, 2, 495-501. [CrossRef]

28. Nielsen, A.E.; Toft, J.M. Electrolyte crystal growth kinetics. J. Cryst. Growth 1984, 67, 278-288. [CrossRef]

29. He, S.; Oddo, J.E.; Tomson, M.B. The nucleation kinetics of barium sulfate in $\mathrm{NaCl}$ solutions up to $6 \mathrm{M}$ and $90^{\circ} \mathrm{C}$. J. Colloid Interface Sci. 1995, 174, 319-326. [CrossRef]

30. Bosbach, D.; Böttle, M.; Metz, V. Experimental Study on Ra ${ }^{2+}$ Uptake by Barite $\left(\mathrm{BaSO}_{4}\right)$; SKB Technical Report TR-10-43; Waste Management: Houston, TX, USA, 2010.

31. Curti, E.; Fujiwara, K.; Iijima, K.; Tits, J.; Cuesta, C.; Kitamura, A.; Glaus, M.A.; Müller, W. Radium uptake during barite recrystallization at $23 \pm 2{ }^{\circ} \mathrm{C}$ as a function of solution composition: An experimental ${ }^{133} \mathrm{Ba}$ and ${ }^{226}$ Ra tracer study. Geochim. Cosmochim. Acta 2010, 74, 3553-3570. [CrossRef]

32. Gilmore, G. Practical Gamma-Ray Spectrometry, 2nd ed.; Wiley: Hoboken, NJ, USA, 2011.

33. International Atomic Energy Agency (IAEA). Reference material IAEA 434: Naturally Occurring Radionuclides in Phosphogypsum; Analytical Quality in Nuclear Applications. Series No. 17; IAEA: Vienna, Austria, 2010.

34. Monnin, C. A thermodynamic model for the solubility of barite and celestite in electrolyte solutions and seawater to $200^{\circ} \mathrm{C}$ and to $1 \mathrm{kbar}$. Chem. Geol. 1999, 153, 187-209. [CrossRef]

35. Templeton, C.C. Solubility of barium sulfate in sodium chloride solutions from 25 to $95^{\circ} \mathrm{C}$. J. Chem. Eng. Data 1960, 5, 514-516. [CrossRef]

36. Ceccarello, S.; Black, S.; Read, D.; Hodson, M.E. Industrial radioactive barite scale: Suppression of radium uptake by introduction of competing ions. Miner. Eng. 2004, 17, 323-330. [CrossRef]

37. Maguire-Boyle, S.J.; Barron, A.R. Organic compounds in produced waters from shale gas wells. Environ. Sci. Process. Impacts 2014, 16, 2237-2248. [CrossRef]

38. Vinograd, V.L.; Brandt, F.; Rozov, K.; Klinkenberg, M.; Refson, K.; Winkler, B.; Bosbach, D. Solid-aqueous equilibrium in the $\mathrm{BaSO}_{4}-\mathrm{RaSO}_{4}-\mathrm{H}_{2} \mathrm{O}$ system: First-principles calculations and a thermodynamic assessment. Geochim. Cosmochim. Acta 2013, 122, 398-417. [CrossRef]

39. Parkhurst, D.L.; Appelo, C.A.J. User's Guide to PHREEQC (version 2)—A Computer Program for Speciation, Batch-Reaction, One-Dimensional Transport and Inverse Geochemical Calculations; U.S. Geological Survey, Water-Resources Investigations Report; USGS: Reston, VA, USA, 1999.

40. Guggenheim, E.A.; Turgeon, J.C. Specific interaction of ions. Trans. Faraday Soc. 1955, 51, 747-761. [CrossRef]

41. Ciavatta, L. The specific interaction theory in the evaluating ionic equilibria. Ann. Chim. 1980, 70, 551-562.

42. Zhu, C. Coprecipitation in the barite isostructural family: 1. binary mixing properties. Geochim. Cosmochim. Acta 2004, 68, 3327-3337. [CrossRef]

43. Kowacz, M.; Putnis, C.V.; Putnis, A. The effect of cation:anion ratio in solution on the mechanism of barite growth at constant supersaturation: Role of the desolvation process on the growth kinetics. Geochim. Cosmochim. Acta 2007, 71, 5168-5179. [CrossRef]

44. Piana, S.; Jones, F.; Gale, J.D. Assisted desolvation as a key kinetic step for crystal growth. J. Am. Chem. Soc. 2006, 128, 13568-13574. [CrossRef] [PubMed]

45. Her Majesty's Stationery Office. The Water Supply (Water Quality) Regulations; UK Statutory Instruments No. 614; Her Majesty's Stationery Office: London, UK, 2016.

46. European Council. Laying down Requirements for the Protection of the Health of the General Public with Regard to Radioactive Substances in Water Intended for Human Consumption; Council Directive 2013/51/Euratom; CEC: Brussels, Belgium, 2013.

47. Olsson, O.; Weichgrebe, D.; Rosenwinkel, K.H. Hydraulic fracturing wastewater in Germany: Composition, treatment, concerns. Environ. Earth Sci. 2013, 70, 3895-3906. [CrossRef]

48. Haghshenas, A.; Nasr-El-Din, H.A. Effect of dissolved solids on reuse of produced water at high temperature in hydraulic fracturing jobs. J. Nat. Gas Sci. Eng. 2014, 21, 316-325. [CrossRef]

49. Zhang, T.; Hammack, R.W.; Vidic, R.D. Fate of radium in Marcellus Shale flowback water impoundments and assessment of associated health risks. Environ. Sci. Technol. 2015, 49, 9347-9354. [CrossRef]

(C) 2020 by the authors. Licensee MDPI, Basel, Switzerland. This article is an open access article distributed under the terms and conditions of the Creative Commons Attribution (CC BY) license (http://creativecommons.org/licenses/by/4.0/). 